you don't." I would like to recommend an article by B.G. Braun (1984). Professor Merskey seems to overestimate the power of hypnosis. As Braun explains, MPD cannot be produced by hypnosis, but it can be unveiled by hypnotic techniques.

BraUN, B. G. (1984) Hypnosis creates multiple personality: myth or reality? International Journal of Clinical and Experimental Hypnosis, 32, 191-197.

Studiegången 17-306

S-41681 Gothenburg

Sweden

Ulla KaRILAMPI

\section{The neglect of anger in Western psychiatry}

SIR: I read with interest the review on anger by Kennedy (Journal, August 1992, 161, 145-153), and fully support the view that the clinical assessment of anger, its antecedents, consequences, and treatability has been neglected. In the handbook on psychiatric examination (Institute of Psychiatry, 1987) which is piously used by psychiatric trainees, mood assessment includes, among others, spirits, anxiety, tearfulness, and guilt, but not anger. Clinically, extreme states of depression or anxiety are readily regarded as a disorder which is out of a patient's own control and requires psychiatric treatment. In contrast, similarly severe attacks of rage are often conceived, if not stigmatised, as being within a person's own moral responsibility, unless the anger is epiphenomenally thought to underlie manifest depression and hence should be 'ventilated'. Unlike sadness or apprehension, anger easily provokes negative countertransference and may selectively be repressed by the psychiatric profession. If morbid anger has a biological basis akin to depression or anxiety and responds equally well (or poorly!) to psychiatric treatment, then many affected subjects may have been unjustifiably sent to prison.

Dr Kennedy may like to add to his review the Chinese concepts of emotions and pathogenesis $(\mathrm{Wu}$, 1982). Traditional Chinese medicine, as recorded in the classical text of Huang-ti Nei-ching (the 'Bible of Chinese medicine') more than 2000 years ago, stresses the importance of a balanced life, and the regulation of the seven emotions ( $q$ i-qing). Instead of a simplistic depression-elation paradigm, the seven emotions include joy, anger, worry, contemplation, sorrow, apprehension, and fright which may dialectically interact with one another. Depression does not rank high among these emotions, explaining to some extent the reputed lack of lexicon to express depression and the controversial issue of there being less depression in the Chinese (Xu, 1987). Excessive emotional activity of any kind may cause imbalance of $Y$ in and Yang, blockade of $Q i$, malfunction of organs and hence illness. More specifically, violent anger is hurtful to Yin, and violent joy is hurtful to Yang. A person with an irascible personality is described as hou-qu-ta rather than 'borderline' among Mandarin-speaking Chinese (Lin et al, 1980). Sorrow counteracts anger, lending some credence to the psychoanalytic theory that anger repressed and turned against the self becomes depression.

In investigating the Korean culture-bound 'anger' syndrome of Hwa-Byung, Lin et al (1992) recently suggest the addition of an 'anger syndrome' in the DSM-III system. Notwithstanding the social risk of legitimising anger and aggression as disease states, morbid anger deserves a fair share of the enormous and not always fruitful research efforts that Western psychiatry has elected to spend on depressive and anxiety states.

Institute of Psychiatry (1987) Psychiatric Examination: Note on Eliciting and Recording Clinical Information in Psychiatric Patients (2nd edn). Oxford: Oxford University Press.

LIN, K. M., KLeinman, A. \& LIN, T. Y. (1980) Overview of mental disorders in Chinese cultures: review of epidemiological and clinical studies. In Normal and Abnormal Behaviour in Chinese Culture (eds A. Kleinman \& T. Y. Lin), pp. 237-272. Boston: D. Reidel.

—, LAU, J. K. C., Yамамoto, J., et al (1992) Hwa-Byung-a community study of Korean Americans. Journal of Nervous and Mental Disease, 180, 386-391.

Wu, D. Y. H. (1982) Psychotherapy and emotion in traditional Chinese medicine. In Cultural Concepts of Mental Health and Therapy (eds A.J. Marsella \& G.M. White), pp. 285-301. Dordrecht: Reidel.

XU, J.M. (1987) Some issues in the diagnosis of depression in China. Canadian Journal of Psychiatry, 32, 368-370.

SiNG LeE

Department of Psychiatry

Chinese University of Hong Kong, Shatin

Hong Kong

\section{The Northfield Experiments}

SIR: As psychoanalysts practising analytic group psychotherapy in a mental hospital, we read with great interest Harrison \& Clarke's paper about the Northfield Experiments (Journal, May 1992, 160, 698-708). It might be of interest to the readers of the Journal to know that there is a psychotherapeutic ward in a state hospital in Switzerland (Haus 14, Kantonale Psychiatrische Klinik Wil, St Gallen) which is explicitly committed to the concepts developed at Northfield. This is the only psychoanalytically orientated unit in a large clinic, and we 